\title{
RESIDENTIAL PROPERTY DEVELOPMENT PROFESSIONALS ATTITUDES TOWARDS SUSTAINABLE DEVELOPMENT IN AUSTRALIA
}

\author{
S. G. Bond \\ Department of Agricultural Management and Property Studies, Lincoln University, New Zealand.
}

\begin{abstract}
Buildings account for around $30 \%$ of the developed countries greenhouse gas (GHG) emissions. Improving energy efficiency of buildings is one of the quickest and most cost-effective ways of reducing GHG emissions. This paper outlines the results of research carried out in Australia in 2009. The broad aims of the research are to identify policy directions to aid in the uptake of sustainability practices that will help improve building performance and reduce GHG emissions. Part of the research entailed surveying building practitioners involved in residential property development to find out their experiences with designing and constructing homes and what they perceive to be the drivers and barriers to the uptake of sustainable building practices. Respondents have seen an increase in demand for energy-efficient 'green' homes, due to an increase in awareness of climate change and also the reduced utility costs associated with these homes. The most common, client-preferred, and successful features incorporated into the design and retrofitting of homes were passive solar design, having gas connected, solar water heating and rainwater tanks. The high sunshine hours in Australia together with the availability of Government rebates and subsidies make these features financially viable. The average cost premium to build a 'green' home was identified as $14.2 \%$ compared to the cost of building a conventional home without energy-efficient features. The main barriers that prevent the incorporation of sustainable features into residential developments were identified as cost and lack of developer awareness. Despite this, two-thirds of the respondents felt that consumers would be willing to pay up to a $10 \%$ premium for an environmentally friendly home. Unfortunately, this falls below the $14.2 \%$ premium identified.
\end{abstract}

Keywords: energy efficiency, greenhouse gas emissions, residential, sustainability.

\section{INTRODUCTION}

Buildings in Australia account for $23 \%$ of Australia's greenhouse gas (GHG) emissions, consume $40 \%$ of Australia's total energy output and the cost to the economy of poor indoor environmental quality is estimated at $\$ 12 \mathrm{~b}$ annually [1]. The most recent National Greenhouse Gas Inventory produced by the Australian Greenhouse Office (AGO, now the Department of Climate Change) reports that Australia's net GHG emissions across all sectors in 2005 totaled 559.1 Mt of carbon dioxide equivalent (CO2-e). By 2010, the residential building sector is expected to produce between 56.7 and $58.1 \mathrm{Mt}$ of CO2-e, while the commercial sector is expected to increase GHG emissions nearly twofold to $63 \mathrm{Mt}$ of CO2-e $[2,3]$. Legislation and government initiatives have been introduced to encourage sustainability in the built environment that will help Australia meet its' Kyoto emission reduction targets.

\section{BACKGROUND AND LITERATURE REVIEW}

In recognition of the significant environmental impacts associated with buildings, in 2003 the Department of Environment \& Heritage (DEH) [4] and others, commissioned a scoping study to investigate whether it was appropriate for sustainability requirements to be included in the Building Code of Australia (BCA). In June 2004, the Australian Building Code Board (ABCB) endorsed some of the key recommendations of the research and announced that sustainability should become a goal of the BCA (alongside the existing BCA goals of health, safety and amenity).

About three-quarters of spending on buildings over the last five years have been on dwellings. About 55\% of this involves construction of new dwellings and $45 \%$ involves alterations and additions 
to existing dwellings over $\$ 10,000$. The remaining $27 \%$ of spending on buildings over the last five years has been for non-residential buildings that have an economic life of between 40 and 50 years [5]. These figures show the importance of a focus on the residential sector due to the size of the spending on these buildings compared to the non-residential sector. Further, as much of the environmental impact of buildings is determined at the design stage it is critical that environmental impacts be considered early in the design process.

The barriers to reducing impacts on the environment highlighted in the DEH \& AGO report include: lifestyle choice whereby people want large houses (current average of $258 \mathrm{~m}^{2}$ ); a trend to smaller household sizes (2.6 persons per household) driving building demand for more dwellings, and resistance to urban densification and consolidation.

At the Council of Australian Governments [6] meeting on April 30, 2009, the States and the Federal Government signed the National Strategy on Energy Efficiency 2009-2020 Memorandum of Understanding (MOU) and released a draft National Strategy on Energy Efficiency (NSEE). The National Strategy is a comprehensive package of measures to overcome the barriers and challenges that prevent the market delivering the actual economic potential of energy efficiency.

Under the NSEE, work commenced on five key measures to drive growth in a number of highly energyefficient homes and commercial buildings across Australia. Those relating to housing are as follows:

- Increasing energy-efficiency requirements for new residential buildings to six stars, or equivalent, nationally in the 2010 update of the BCA, as well as introducing new efficiency requirements for hot-water systems and lighting.

- Phasing in mandatory disclosure of residential building energy, greenhouse and water performance at the time of sale or lease, commencing with energy efficiency, from May 2011.

- Reforming current building energy-efficiency standard and assessment processes to achieve consistency across the nation.

According to a report by Environment Victoria et al. [7], 'By 2010, emissions from buildings are estimated to increase by more than 48 percent above 1990 levels. Yet GHG emissions from the average home can be reduced by more than 75 percent with energy efficient design and appliances,' (p. 4). The report states that as new homes will account for just 15 percent of Australia's housing stock by 2020 , a focus solely on standards for new homes will not achieve the 'mass greening' of our housing stock we need, and a concerted program to upgrade the energy and water efficiency of the existing housing stock is needed as well. In recognizing this need, the Government has introduced initiatives to improve the energy efficiency of homes including the 2009 Home Insulation Program, Green Loans Program, and Solar Hot Water Rebate. However, due to various issues arising with these schemes they were abolished in February 2010. A Renewable Energy Bonus Scheme (REBS) commenced on 1 June 2010 to replace the Home Insulation Program and the Solar Hot Water Rebate, but no longer includes an insulation program. A completely new Green Start Program was to commence from 1 January 2011 replacing the Green Loans Program, but this has now been canceled after various reviews and instead the Green Loans Program was extended to February 28, 2011, with $\$ 30$ million set aside from the closure of the Green Loans and Green Start Programs to assist un-contracted Green Loans assessors and support accredited assessors to receive further training.

The uptake of these initiatives has been mixed. Barriers to uptake have been identified in a report by Environment Victoria et al. [7]. These include lack of consumer information at the point of purchase or lease, or high degree of complexity or time commitment leading to inefficient choices; split incentives between builders and the householder where builders are not motivated to improve the energy efficiency of homes because they do not re-coup the benefits of lower-energy bills or improved 
comfort that accrue to the householder; upfront capital costs of energy-efficiency measures; and 'bounded rationality'-householders may not understand the benefits to them of energy efficiency, or may not act due to other priorities.

\subsection{Purpose of the conducted research}

Despite the incentives to build more sustainably such as legislation, Building Code changes, and financial incentives, there is little research of the perceptions of those that actually produce the buildings. The aim of this research is to survey those producers (architects, developers, and builders) and investigate what they perceive the main drivers and barriers to residential sustainable development to be. As these stakeholders are major participants in the process of 'greening' Australian buildings it is important to know their views. Assessment of the results will provide a range of potential policy directions to aid in the uptake of sustainability building practices for new and existing buildings.

\section{RESEARCH METHODOLOGY}

This study is part of an Australian Research Council Discovery grant with Professor Peter Newman titled 'The drivers and barriers to sustainability in residential and commercial buildings.' A survey of practitioners involved in property development was conducted in 2009 to determine their contribution to sustainable development, and thus climate change, and what they perceive the drivers, barriers, costs and benefits to be in designing and constructing sustainable building solutions.

\subsection{Methodology}

To investigate building practitioners' experience with residential sustainable development and to determine their perceptions of what the main drivers and barriers are to this form of development a postal survey was adopted. This was considered the quickest and most cost-effective method of surveying a large sample of residential building practitioners across Australia. In addition, an online survey was developed with the aim of increasing the potential number of survey respondents, in particular those respondents that would prefer to respond electronically than by hardcopy. The responses received were individually coded, entered into a computerized database, and analyzed.

\subsection{The postal survey}

A covering letter describing the survey, the questionnaire, and a self-addressed prepaid envelope were mailed to residential building practitioners in July 2009 with a requested response date of August 10. As the questionnaires could be returned anonymously, no formal reminder strategy was able to be used to target individual non-responders. Instead an email was sent out to all respondents as a reminder to respond if they had not yet done so.

\subsection{The online survey}

Using a web-based survey creation software, the paper-based survey was then created online to closely match the wording, layout, and response style. Due to limitations in the way the online survey could be formatted and created, the paper-based version was then modified, where required, to closely represent the online version of a particular question. This helped to ensure consistency in the survey responses collected through each version: paper-based and online. 


\subsection{Database}

A database of both mainstream and green building practitioners was developed using a variety of sources but primarily builder respondents in New South Wales (NSW), Victoria (VIC), Queensland (QLD) and Western Australia (WA) were sourced from state chapter web sites of the Master Builders Association (MBA) and the Australian-wide property web site, Realestate.com.au. The Yellow Pages were the main source of contacts for both mainstream and green builders in Tasmania. These states were selected based on Australian Bureau of Statistics December 2007 estimated population estimates for the states. Only four states were to be included originally, but advice from a sustainability architect suggested including Tasmania, even though the population is smaller than that in South Australia, due to the relatively higher level of residential green building awareness and development in that state. The larger and widely known practitioners and companies were selected based on the assumption that they would have more experience in development than a smaller, lesser known individual or company.

The individuals and/or companies sourced above were then researched using Google, White Pages, and Yellow Pages in order to obtain a web site (if available) and a postal address. The web site search was also used to try to determine if the builder advertised 'sustainable/green/eco' building practices as the goal was to survey both 'mainstream' and 'green' builders/developers. The web site search also helped to identify the name of an appropriate or high ranking member of staff (to limit the number of surveys addressed to 'The Manager', with the aim of increasing the response rate) and an email address for survey response follow-up, if required.

A total of 394 potential respondents were identified. However, it was not clear in all cases from the sources used whether the individuals or companies focused solely on residential, and it is possible that the database included names of individuals/companies that were involved with either residential and commercial property development or just one of these development types. As the survey questions had a residential focus it was expected that commercially focused respondents would either not answer it, or would make it clear it was not suitable for them to answer as they did not work in residential property.

\subsection{Survey instrument}

The questionnaire included initial questions to identify which professional group the respondent identifies with and whether they have seen an increase in demand for sustainable, energy-efficient homes.

Specific questions were asked about what type of sustainable features they incorporate into homes, and the most successful energy-efficient ideas they have implemented in buildings. Next, questions were asked about the barriers to incorporating sustainable features in developments and what more could be done to improve the uptake of these features.

As cost has been identified as a perceived barrier to the uptake of sustainable practices, a question was asked about the average cost to build a conventional home versus a sustainable, energy-efficient home to see if this perception has any substance. To identify the most effective features in achieving sustainable outcomes open-ended questions were asked about what design features and building materials would be used to achieve an optimal outcome.

The next set of questions relate to the energy performance of homes. One issue that commonly arises with sustainable buildings is that they are not used by the occupiers in a way that they were designed to be used, so a question was asked to determine the respondents' perception of this and the reasons they think it may occur. Next a question was asked about the energy savings from specific sustainable features. 
Two questions were asked about what respondent's perceive would be a reasonable cost premium that consumers would be willing to pay to have sustainable features in their home and their perceptions of what the most important financial and non-financial benefits of these features are to a consumer. Finally, demographic questions were included at the end of the survey, in addition to questions about their role in their company and where their company is located and the type of development that they are involved with.

\section{CASE STUDY FINDINGS}

Of the 394 questionnaires mailed to residential building professionals, $10.15 \%$ were completed and returned. We achieved another 32 responses from the online survey (21 complete and 11 partially completed), to give an overall response rate of around $18 \%$. While this response rate may seem low, it may reflect the small number of practitioners actually involved in sustainable development, or that have an interest in, or knowledge of, this form of development. As such, the mainstream practitioners in the sample may have felt they do not have the expertise to answer the survey questions.

The majority of the respondents classified themselves as builders (60\%), 35\% as architects and $32 \%$ as developers. Nearly three-quarters $(71 \%)$ of the respondents had seen an increase in demand for more energy-efficient, sustainable homes. The reasons given for this were the cost savings that can be achieved and increased climate change awareness. It was felt that the increased demand may become even more apparent as energy prices increase and mandatory disclosure of energy efficiency is introduced. Government rebates and tangible factors such as droughts have helped drive this demand.

Respondents were then asked to specify the proportion of the developments undertaken in the last two years that incorporate various specified features. The most common features included in 91-100\% of their developments were passive solar design, rain water tanks, and solar water heating. Given the high sunshine hours in Australia and the solar water heating and rain water tank rebates available, these results are not surprising. Further, as solar passive design is the most cost-effective strategy to achieve energy efficiency, this outcome was also not surprising, and as one respondent noted this is just 'good common sense'. The detailed results are outlined in Table 1.

The features respondents listed under 'other' included recycled building materials, water-efficient fittings (e.g. low flow showerheads), and low-wattage light fittings (e.g. compact fluorescent/LED).

Table 1: Proportions and types of sustainable features.

\begin{tabular}{lcc}
\hline Types of ES features & Valid response (\%) & $\begin{array}{c}\text { Proportion of development/ } \\
\text { response rate }\end{array}$ \\
\hline Passive Solar Design & 54 & $91-100 \%: 46 \%$ \\
Rain Water Tank & 54 & $91-100 \%: 39 \%$ \\
& & $1-10 \%: 23 \%$ \\
Solar Water Heating & 47 & $91-100 \%: 23 \%$ \\
Double Glazing & 38 & $1-10 \%: 34 \%$ \\
Grey Water System & 36 & $1-10 \%: 31 \%$ \\
PV Panels & 33 & $1-10 \%: 42 \%$ \\
Other & 3 & \\
\hline
\end{tabular}


The demand for these features is coming from both the respondent advice to their clients (72\%) and to a lesser extent (63\%) from the client themselves. But government regulation was also listed as a driver.

The respondents were asked to rank the most preferred sustainable features incorporated into the design of new homes and when retrofitting existing homes, from the client perspective. For new homes, the most preferred features selected were solar passive design, and connected to gas being next for new houses. The least preferred was photovoltaic (PV) panels. It is not surprising that these rankings also reflect cost, with the most preferred being the cheapest to incorporate and PV panels being the most expensive. For retrofitting homes, the ranking changed slightly with connected to gas most preferred, and solar water next to the least preferred being double glazing. Again, these rankings tend to reflect cost and also available rebates. The full rankings are shown in Table 2.

The most common reason given for ranking solar passive design highest was that it is the most cost-effective way of creating an energy-efficient design and is common sense good design. The common reason that PV panels were ranked the lowest for new homes was due to the cost and long payback periods.

Connected to gas was considered a cheap electricity option for clients. Solar water heating was considered a good cost-effective alternative to gas water heating especially where rebates are available. In some States solar water heating and rain water tanks are a government requirement if the home is to have a 5-star rating. Respondents perceive that clients really like rain water tanks especially in areas where there are water shortages. Double glazing was considered to be expensive and unnecessary, especially in a warm climate, with some considering that it is not an Australian solution except for noise reduction. The issues with grey water systems were considered to be cost and difficulty getting council approval (in jurisdictions where they are in fact permitted). Connecting to gas and double glazing a home were considered more expensive to retrofit in an existing home than including it in a new home.

To find out the most successful energy-efficient ideas implemented, respondents were asked to list these under various building scenarios from new buildings to partial refurbishment. The most successful, especially at the new build phase is passive solar design and correct site orientation. Increased high $R$-value insulation in the ceiling, walls, and under floor, high performance and/or double glazing, and solar hot water were listed by many respondents. Rainwater tanks, PV panels, and use of recycled materials were listed less commonly as options.

One respondent mentioned that the design stage is the key to energy efficiency but another noted that speculative developers' look to maximize profits by minimizing construction costs and that good design may sell but that it tends to be in terms of aesthetics and perceived lifestyle than in energy-efficiency terms. In terms of complete refurbishment emphasis was placed on improving the building fabric.

Table 2: Energy-saving features.

\begin{tabular}{lll}
\hline Rank & \multicolumn{1}{c}{ New homes } & Retrofitting existing homes \\
\hline 1 & Passive Solar Design & Connected to Gas \\
2 & Connected to Gas & Solar Water Heating \\
3 & Rain Water Tank & Rain Water Tank \\
4 & Solar Water Heating & PV Panels \\
5 & Double Glazing & Grey Water System \\
6 & Grey Water System & Double Glazing \\
7 & PV Panels & Others \\
8 & Others & \\
\hline
\end{tabular}


Respondents were asked to rank items that prevent the incorporation of sustainable features into residential developments from the most to the least significant barrier. An unwillingness to pay the additional cost of features and lack of developer awareness were ranked as the top two most significant barriers with unreliable/unproven technology listed as the least significant barrier (Table 3).

Other barriers listed by respondents were lack of national regulation and industry education and skills, the split-incentives between developers and owners/occupiers, and payback periods for sustainable products being too long. As noted by one respondent, once power, water, and petrol prices increase, these barriers will change.

While it was felt there was generally good access to information a number of respondents were concerned about the quality of the information due to 'green wash' and inaccurate information. Respondents were asked to rank items that they think would improve the uptake and incorporation of energy- or water-saving features into the design of new and retrofitted homes. Respondents feel that more rebates and subsidies would have the strongest influence. This result is consistent with the feedback from the previous question, which found that unwillingness to pay additional cost is the primary barrier for incorporating sustainable features. The least important item for encouraging sustainable features in new homes was the availability of products, and for retrofitting homes it was mandatory energy-efficiency reporting (Table 4).

Table 3: Barriers to sustainable development.

\begin{tabular}{ll}
\hline Rank & \multicolumn{1}{c}{ Barriers } \\
\hline 1 & Unwillingness to pay additional cost \\
2 & Lack of developer awareness \\
3 & High cost/low benefit \\
4 & Lack of owner/occupier awareness \\
5 & Poor access to information \\
6 & Low consumer demand \\
7 & Limited availability to new technology \\
8 & Unreliable/unproven technology \\
9 & Others \\
\hline
\end{tabular}

Table 4: Incentives to sustainable development.

\begin{tabular}{lll}
\hline Rank & \multicolumn{1}{c}{ New homes } & \multicolumn{1}{c}{ Retrofitting existing homes } \\
\hline 1 & More rebates/subsidies & More rebates/subsidies \\
2 & Building code changes & Building code changes \\
3 & Change in legislation & Change in legislation \\
4 & Building certification and mandatory & Better advertising \\
& energy-efficiency reporting & \\
5 & Better advertising & Building certification \\
6 & Availability of products & Availability of products \\
7 & Others & Mandatory energy-efficiency reporting \\
8 & & Others \\
\hline
\end{tabular}


More rebates/subsidies were said to encourage both uptake and early adoption of new technology but means-testing tended to discourage uptake. It was pointed out that Building Code changes mostly impact on new build, not on existing buildings. Further, the Building Code mandates a minimum standard, but it was felt more could be done, including disallowing black roof tiles which absorb heat. Better information through advertising and less 'green wash' was considered important to help increase both awareness and demand, but that this will not overcome the issue of split incentives between owner/occupier.

There was a mixed reaction to legislative changes with some respondents reporting discontent about change being forced upon them, while others felt that a range of legislation is needed to overcome barriers to sustainable development. The proposed carbon scheme (emissions trading plan) was provided as an example of how this would increase energy and water costs that would encourage people to conserve. Further, it was considered that legislation evens out the playing field for builders and developers who would be disadvantaged by going green through increased costs. There was also mixed reaction to building certification with some feeling this was open to manipulation and does not compel builders to comply, while others felt that it would increase consumer awareness, facilitate equitable comparison and informed choice, and educate owners.

Availability of products was not considered a major driver, but it was felt that demand is not significant enough to reduce the cost of these. Mandatory reporting was considered to be onerous due to the added time and cost involved in meeting requirements and which further raises affordability issues that would act as a disincentive.

Questions were asked about the average size home and average costs per square meter to build a standard home compared to a sustainable energy-efficient home and the associated cost premium to build 'green'. The average size of a home was reported to be $235 \mathrm{~m}^{2}$, however, reported average sizes ranged from 90 to $400 \mathrm{~m}^{2}$ indicating perhaps that the figures quoted were for both single dwellings and apartments. The average cost to build a standard home was $\$ 1540 / \mathrm{m}^{2}$ (range from $\$ 640$ to $\$ 3,200 / \mathrm{m}^{2}$ ), while the average cost to build a sustainable, energy-efficient home was $\$ 1888 / \mathrm{m}^{2}$. The average cost premium to build a 'green' home was $14.2 \%$ (range from 0 to 33\%). There was variability in the answers which may reflect the type of developments being built (single family homes, townhouses, and apartments) and the location, as costs vary across the country.

Similar to a previous question about successful features used in green buildings, questions were asked about what design features and building materials are most effective in achieving positive sustainable building outcomes (Table 5). Some non-mainstream materials were listed which seem to be gaining penetration in the market such as 'Hebel' a lightweight autoclaved aerated concrete cladding with excellent thermal insulation properties and good acoustic performance.

One respondent said that the installation of grid-connected solar PV-reduced electrical energy use, but was 'lost' through excessive use of air conditioning (heating cycle) due to a maladjusted thermostat. They went on to say that the lack of provision and willingness by the energy authority to show the gross energy use, and gross energy-saving contribution (through grid connection feedback of electricity) showing only a net adjustment, which was minimal and resulted in the owner thinking that the solar PV system was not worth the cost, without realizing how much it was actually reducing energy-running costs by. This is a disconcerting observation as such an outcome would act as a disincentive to invest in energy-efficient features.

The next question was to determine respondents' knowledge of the energy savings of individual components of the structure (Table 6). Half of the respondents chose not to answer this question and of the remainder that did less than $20 \%$ had any knowledge of the energy savings of the listed features. The few respondents $(5.5 \%)$ that stated the cost savings for each item varied widely in their estimates, but perhaps this indicates the difficulty in modeling due to the numerous variables involved 
Table 5: Effective sustainable features.

\begin{tabular}{ll}
\hline Design features & \multicolumn{1}{c}{ Building materials } \\
\hline Passive solar/orientation & Green board \\
Window sizes and window treatments & $\begin{array}{c}\text { Thermal mass (e.g. concrete slab, brick, clay, } \\
\text { rammed earth, straw bale, and mud brick) } \\
\text { Sustainable grown timber }\end{array}$ \\
Eaves/shading & Local and/or recycled materials \\
Insulation & Reverse brick veneer \\
Double glazing & Comfort-plus double glazing \\
Solar hot water & Energy-efficient fittings \\
Rainwater tanks & Concrete, polystyrene, concrete sandwich cladding \\
PV panels & Hebel - a lightweight autoclaved aerated concrete \\
Grey water recycling & building material \\
\hline
\end{tabular}

Table 6: Energy savings.

\begin{tabular}{lccc}
\hline Features & \% Response & Valid \% & Energy savings (\%) \\
\hline Passive Solar Design & 6.9 & 13.9 & $10-60 \%(n=4)$ \\
PV Panels & 9.7 & 19.4 & $10-100 \%(n=5)$ \\
Solar Water Heating & 8.3 & 16.7 & $40-90 \%(n=3)$ \\
Connected to Gas & 8.3 & 16.7 & $18-25 \%(n=4)$ \\
Double Glazing & 5.6 & 11.1 & $10-40 \%(n=3)$ \\
Efficient Lighting & 8.3 & 16.7 & $8-80 \%(n=3)$ \\
Others & 1.4 & 2.8 & \\
Missing Data & 50.0 & 0 & \\
\hline
\end{tabular}

(e.g. number of windows, building fabric, shading, and orientation). The lack of energy-savings knowledge was of concern as without it, it would be difficult to convince consumers of the advantage (financial) of having these items other than for altruistic reasons (doing the right thing for the environment).

Two-thirds of the respondents think that consumers weigh up the costs and benefits of individual energy-saving features. This being the case it is surprising that not more of the respondents knew what these energy savings were.

As the practitioners are developing housing for their client's, the last few questions asked respondents for their perceptions of what consumers (their clients) consider would be an acceptable level of additional cost for incorporating energy/water-saving features into a home and to rank what they consider the most important benefits of these features to be. Similar questions were included in a follow-up survey to householders. It will be interesting to compare the results of these, once known.

Over a third felt that consumers would be willing to pay between $1 \%$ and $5 \%$ more, while $30 \%$ would be willing to pay $6 \%$ and $10 \%$ more for these features. However, $12.5 \%$ of respondents felt that consumers would not pay any more for these features. Some respondents commented that it 
Table 7: Benefits of 'green buildings'.

\begin{tabular}{ll}
\hline Rank & Financial and non-financial benefit \\
\hline 1 & Cost savings (e.g. > $\$ 1000$ p.a.+) \\
2 & Increased property value \\
3 & Doing the right thing \\
4 & Healthy indoor air quality \\
5 & Decreased obsolescence \\
6 & Others \\
\hline
\end{tabular}

depended on the socioeconomics of the area and on the potential savings and payback periods. It is encouraging that at least the majority of respondents felt that consumers would be willing to pay a premium for energy-conserving features.

Table 7 indicates what respondents consider the most important financial and non-financial benefits to be of energy-saving features. Not surprisingly, the financial benefits were most important, with cost savings and increased property values ranked in first and second place, respectively.

Despite cost savings being ranked first, according to one respondent, 'spurious claims and lack of statistical data cause cost savings to be doubted'. Another respondent felt that cost savings was a particularly strong driver when utility costs are rising and when there are water shortages.

One respondent noted that clients believe that there is a growing market for sustainable housing but only if this can be measured and they observe that the valuation industry is still working through the issue of 'how to value green'. 'Doing the right thing' was considered important 'until it cost money' as one respondent highlighted. 'Most people are just trying to survive and earn a living.' Healthy indoor air quality was considered to be increasingly important, particularly as awareness increases of allergenic causes and air quality pollution.

Evaluation of the responses to the questionnaire's background questions revealed that $71.6 \%$ of the respondents were male and $28.4 \%$ were female. Over a third (37\%) of the respondents were from Victoria, 22\% from Western Australia, 12\% from Queensland, 10\% from New South Wales, 7\% from Tasmania, and 7\% operating in more than on state, with $2 \%$ operating in Australasia. This indicates a reasonable national geographical spread of respondents. The roles respondents held within their company were mostly at the management level: $46 \%$ directors, $20.5 \%$ managing directors, $13 \%$ general managers, and $18 \%$ identifying with a range of individual roles from action visionary to sustainability and design consultant. This high level within the company gives some confidence in their ability to answer the survey questions. Nearly three-quarters of respondents are involved in medium to high cost development, $45 \%$ in low to medium cost, $23 \%$ in high cost, and $12 \%$ in low cost developments, indicating the majority of their work is in the medium to high cost housing market.

Finally, the respondents were invited to make additional comments. One respondent noted that there are quite a number of innovative options for green building systems but they all focus on the product and insulation potential. Further, the respondent felt that building green needs to be looked at in conjunction with what the public at large will accept (public perception) and raised a number of questions that are outlined in Section 6 Further Research.

Another respondent believes that market demand is the only driver for sustainable development as they claim that developers will only operate to the lowest common denominator as a rule (i.e. highly cost-competitive, standard specification project-type product), until people insist that we have to do 
better. They also note that a holistic approach is necessary and give the example that there is no point in building a sustainable, off-the-grid home $70 \mathrm{~km}$ from a person's workplace. Any benefits of the building will be immediately offset by the increased transport costs.

One respondent pointed out that different design features and building materials need to be incorporated into rating tools that take account of different climate zones so that fair comparisons between ratings can be made. They gave the example that an 8-star home in Melbourne may require a 10-12\% cost premium to build whereas the same home to achieve 8-stars in Albury-Wodonga (a twin city North of Melbourne, separated by the Murray River) may be up to 30-40\% more expensive to build. This respondent also called for an across-the-board energy-efficiency rating tool that rates the real performance of homes, as they claim that the current system is too susceptible to 'fiddling' to get the rating and that no-one checks on the rating of the built house. They give examples of builders who double-glaze one east window and not the one next to it, just to get the rating and keep costs down, and insulation that is not checked for correct installation (the size of Batts used, how it was installed, whether a draught strip is used).

There were a number of suggestions made about what legislators could do to encourage sustainable development. The need to prioritize between affordable housing and energy efficiency (e.g. costs of rainwater tanks make up $4 \%$ of the cost of a low cost home to supply water but use extra power for the pump, yet if it was incorporated in the initial subdivision would cost considerably less per lot development). The need for incentives such as higher feed-in tariffs for PV systems and stamp duty rebates on energy-efficient homes. Further, the builders/developers need incentives to incorporate green living initiatives into developments.

Lastly, the need to take the embodied energy into account in the production and transportation of building materials was highlighted, and the need to overcome confusion in terminology between an energy-efficient home and a sustainable home (one made from sustainable materials). Ideally, the home should be both energy efficient and sustainable.

\section{CONCLUSIONS}

This paper outlines the results of research carried out in Australia in 2009 to identify building practitioners' attitudes toward sustainable, energy-efficient homes, and the type of energy-saving components that are most preferred and successful. A number of issues were raised in the results and barriers identified that need to be overcome to increase the uptake of sustainable, energy-conserving residential development across Australia that will aid the shift toward a low-carbon future. Some of these are discussed further below with recommendations and policy directions suggested.

A barrier to increasing the uptake of energy-efficient and sustainable features in homes that was identified by this research was the lack of national regulation, and lack of industry education and skills. Fortunately, the recently released NSEE will help overcome the lack of national regulation through increasing energy-efficiency requirements for new residential buildings in the 2010 update of the Building Code of Australia; the phasing in mandatory disclosure of residential building energy, greenhouse and water performance at the time of sale or lease, and reforming current building energy-efficiency standard and assessment processes to achieve consistency across the nation. Providing relevant education and training to increase developer awareness and skills would help promote the uptake of sustainable development.

A significant barrier that prevents the incorporation of sustainable features into residential developments was identified as an unwillingness to pay the additional cost of these features. Respondents felt that more government financial incentives are needed to encourage changes in consumer behaviour such as higher feed-in tariffs for PV systems and stamp duty rebates on 
energy-efficient homes. Further, the builders/developers also need incentives to incorporate green living initiatives into developments. The lack of information identified about the energy savings, the GHG emissions saved, costs and payback periods of energy/water-efficiency and sustainable features is causing confusion in the market further making it difficult to convince consumers of the financial advantage of having these items other than for altruistic reasons. Thus, in addition to the government's financial assistance, clear, transparent, easy to understand information is required to help household consumers make informed purchasing decisions regarding their homes and appliances that they use within this, that relate to the environment.

A rating tool is needed that allows for different design features and building materials that take account of different climate zones, so that fair comparisons between ratings can be made. Further, built homes need to be checked/audited to ensure that the 'as built' home matches the design upon which the initial rating was obtained. This would avoid situations where builders cut corners to minimize costs such as double-glazing only visible windows or using insulation that is not the correct size. Such a scheme would have overcome the need to withdraw the Home Insulation Program that suffered intensive public criticism due to fires caused by incorrect installation. A minimum of 150,000 safety inspections of homes were required, at a huge cost to the government, to provide a level of assurance to households that their properties have been inspected and are considered safe. This would not have been required if there had been an auditing system in place, such as that recommended here.

As buildings need to be used in a way that maximizes the energy or resource use performance, as designed, there is the need for more education about both building use and energy use. Smart Metres that detail a consumer's energy use on a real-time basis provide both an educational and motivational tool. When consumers can see where, how and when they use energy they are better informed of how to change behaviour. A number of countries are rolling out Smart Metres for this reason. The energy authorities need to help this process too, by showing full details where solar PV systems or other decentralized renewable energy systems are providing energy back to the grid to reflect the true benefits of these systems (rather than net amounts which tend to hide these benefits).

While new technology, products and techniques are available to aid the process of providing buildings that are energy and water conserving and kinder for the environment, future research could focus on answering the following questions relating to the entire building and life cycle process:

- How publicly acceptable are these solutions? For example, recycling sewage water for drinking is technically possible, but is it publicly acceptable?

- Do these systems integrate into standard building methods?

- How are they viewed by associated trades (does it make their job easier or harder)?

- What is the labour resource required for the new product or system?

- How much retraining is involved to make it mainstream?

- What is the longevity of the product?

- What effect does the product have on the environment once it has reached the end of its usable life e.g. concrete/polystyrene mixed products?

Answers to these questions will provide a holistic overview of how appropriate proposed environmental solutions are in the building process: environmentally, economically, and socially. These answers, together with overcoming the barriers identified in this paper, will help the Australian residential building industry contribute to addressing climate change. 


\section{ACKNOWLEDGEMENTS}

This research was supported under Australian Research Council's Discovery Projects funding scheme (project DP0985410). The views expressed herein are those of the author and are not necessarily those of the Australian Research Council.

\section{REFERENCES}

[1] Green Building Council Australia, Australia's buildings can play a major role in the fight against climate change, available at www.gbcaus.org/gbca.asp?sectionid=5\&docid=1413, 2007 (accessed 16 January 2008).

[2] Australian Greenhouse Office, Australian Residential Building Sector Greenhouse Gas Emissions, 1990-2010, available at www.greenhouse.gov.au/buildings/publications/ residential.html, 1999 (accessed 20 December 2007).

[3] Australian Greenhouse Office, Australian Commercial Building Sector Greenhouse Gas Emissions, 1990-2010, available at www.greenhouse.gov.au/buildings/publications/commercial.html, 1999 (accessed 20 December 2007).

[4] Department of Environment \& Heritage, Australian Building Codes Board, and the CRC for Construction Innovatio), Sustainability and the Building Code of Australia, a scoping study edited by Ashe, B. and prepared by Newton, P. et al., available at www.construction-innovation. info/images/pdfs/Final_Report_2001-013-B-01.pdf, 2003 (accessed 31 January 2008).

[5] Department for the Environment and Heritage and Australian Greenhouse Office, Scoping Study to Investigate Measures for Improving the Environmental sustainability of Building Materials, report prepared by the Centre for Design, RMIT University, Melbourne et al., available at www.climatechange.gov.au/buildings/publications/pubs/building-materials.pdf, 2006 (accessed 15 January 2008).

[6] COAG, Action on energy efficiency and renewables, Media Statement 20 April 2009, available at http://www.alp.org.au/media/0409/msccwenhpm300.php, 2009.

[7] Environment Victoria, Australian Conservation Foundation, the Alternative Technology Association, Friends of the Earth and the Moreland Energy Foundation. Towards climate safe homes:the case for zero emissions and water saving homes and neighbourhoods, September, available at http://www.apo.org.au/node/19020, 2009 (accessed 5 June 2010). 